\title{
THE SURROUNDING AND THE SURROUNDED. DYNAMIC CITY-SUBJECT RELATIONS IN THE LIGHT OF EXISTENTIAL SEMIOTICS
}

\author{
Katarzyna Machtyl \\ Adam Mickiewicz University in Poznań, Poland \\ machtylk@amu.edu.pl
}

The article presents the study of urban space form the existential semiotics point of view. The main notions presented in this paper are the surrounding (i.e. the environment - landscape - city space) and the surrounded (subject an individual human body). Maintaining the structuralist way of semiotic thinking, the author refers to the concepts of Ferdinand de Saussure (langue and parole), Algirdas-Julien Greimas (englobant / englobé), Michel de Certeau (strategies and tactics) and finally Eero Tarasti (existential semiotics, highlining the figure of the subject). The nature-culture relation discussed here is being presented in the perspective of biosemiotics also. The main part of the article contains the author's proposal of applying Tarasti's concept to the city space: firstly, his concept of the landscape semiotics (from 2000) and next the concept of the dynamic "Z-model" (from 2015). As the result, there is presented a complex semiotic study of the city space in the frame of the paradigm of existential semiotics.

Keywords: semiology, structuralism, existential semiotics, biosemiotics, nature-culture relations, landscape, urban space, subject, environment, Z-model, surrounding, surrounded, tactics, strategies.

DOI 10.23951/2312-7899-2019-1-106-119

While shaping his concept of existential semiotics, Eero Tarasti, a Finnish semiotician and musicologist, noted that "for the landscape theory which strives for such a generality, a semiotic approach offers a fruitful perspective. The science that would study the landscape as a kind of sign language should thus be called landscape semiotics" [Tarasti 2000, 154]. Constructing this thought on structural foundations, he noticed that one of its main pillars is the distinction between nature and culture. Fifteen years later, in a book which is a development of the previously outlined theory, he introduces many new concepts, including the so-called "Z-model", used to describe the relationship between man and society, but which can be successfully applied to various areas of culture and human life, including urban space, as I will try to demonstrate. 
Nature - Culture - Biosemiotics: complex relations

The nature / culture distinction was basically at the heart of the structuralist thought. From Claude Lévi-Strauss to semioticians of the Tartu-Moscow School, this division was fundamental to their concepts. There is no place here to address the whole complexity of this opposition in the structuralist perspective; besides, it is well researched in the literature of the subject. After Tarasti we shall only recall one of the statements made by Algirdas-Julien Greimas on the relation between a human being and environment. In the chapter Signs Around Us Umwelt, Semiosphere and Signscape, Tarasti reviews the selected approaches towards the relationship between man and natural environment adopted by humanities. He evokes such notions as Greimas' surrounding and surrounded (englobant / englobé), or environment. This opposition is also the first part of the title of my text. Naturally this opposition writes into the opposition's characteristic of structuralism, patterned on Saussure's signifier and signified, such as the symbolizing and symbolized or the signifying and signified.

A different approach to the nature / culture distinction is proposed within the framework of biosemiotics. Here, referring to its American sources, it is claimed that the opposition between nature and culture is unsustainable, because nature is, in a sense, also an element of culture, which is why semiotics of culture can also successfully deal with the issues of nature. Thus, biosemiotics explores, among other things, the relationships between man and the natural environment in which he lives, but also, for example, by moving to a more detailed level, the functioning of wild birds in urban space, or the place of trees in cities. Therefore, biosemiotics looks at the studied problem holistically, concentrating efforts on mutual relations rather than on separating these two spheres as if by force. Interestingly, and perhaps even surprisingly, Tarasti, who represents existential semiotics, not biosemiotics, notes that both these sub-disciplines have a lot in common: "to our surprise, biosemiotics and existential semiotics agree. They share a central claim, namely, that the environment does not dominate the subject but, rather, the other way round: the subject determines the environment" [Tarasti $2015,117]$. It is the subject, particularly distinguished in existential semiotics, that influences the environment by his various choices: "Yet, since these [surrounding - added by the author] structures are essentially arbitrary and not dictated by nature, they can be changed, and it is the subject which has the power to change them! On this point - that the subject can make its own possibilities - biosemiotics and existential 
semiotics agree" [Tarasti 2015, 118]. The causality of the subject and the related concept of multiple possibilities characterize both biosemiotics and existential semiotics. To sum up this part of Tarasti's deliberations, he proposes to capture the various subject-environment relations in the form of taxonomy, where nine logical cases have been distinguished and described with logical symbols, where $\mathrm{S}$ stands for the subject and $\mathrm{O}$ for the object in the sense of the environment, similarly to E:

1. $\mathrm{S} \wedge \mathrm{O}$ "The subject has been conjuncted with the environment; i.e., there is harmony between them. The subject is a part of its environment".

2. $S \vee E$ "The subject has been disjuncted from its environment; the subject is separated from its milieu".

3. $\mathrm{S} \rightarrow \mathrm{E}$ "The subject wants, strives for and towards his environment; he tries to become assimilated with it".

4. S $\leftrightarrow \mathrm{E}$ "The subject wants to be detached from its environment, $<\ldots>$ to distinguish itself from it".

$5 . \mathrm{S} \neq \mathrm{E}$ "The subject is indifferent to its surroundings".

6. S "The subject has no environment; it is alone in this world; the environment has been excluded $\langle\ldots>$ this is like a sender of message without a receiver".

7. E "The mere environment, without any center. For instance, network models are like that. They have no central point, but they are omnipresent".

8. $S=\rightarrow Y$ "The subject tries to dominate its environment $\langle\ldots\rangle$, the subject creates a semiosphere suitable for itself".

9. $\mathrm{S} \leftarrow=\mathrm{Y}$ "The environment dominates the subject. The subject is subordinated to the dictatorship of conditions" [Tarasti 2015, 128-130].

I think that the strategy that best describes the subject-environment relationship in the context of urban space is strategy number eight: "The subject tries to dominate its environment $\langle\ldots\rangle$, the subject creates a semiosphere suitable for itself" [Tarasti 2015, 129]. It should be noted that when establishing a city, man must somehow dominate the appropriated space, subordinate it to himself, his needs, harness it and make it suitable for himself. Such an action may be either extremely oppressive, paying no attention to anything other than the achievement of one's own goals, or it may try to enter into a dialogue with the appropriated space. However, it is always the entity that will be in a dominant position in this case. What is interesting, we can, I think, notice in urban space also the implementation of other strategies, such as the first strategy, which seems to be the most utopian among those mentioned here, but we can imagine that the desire to put it into practice can be very tempting. The second strategy, based on a logical alternative, assumes 
the separation of the sets: man and his environment. We can imagine here, for example, a kind of alienation of man from his environment, a total lack of mutual relations. In urban space such a situation may occur even in the case of different separation places, prisons or hospitals, but also in a situation where the subject only experiences a sense of alienation, although it does not occur physically.

The seventh strategy is also interesting from our perspective: E "The mere environment, without any center. For instance, network models are like that. They have no central point, but they are omnipresent" [Tarasti 2015, 129]. I think it is worth juxtaposing it with the concept of Marc Augé's non-places, i.e. places that are somehow empty, transferable, only "along the way". "The space of a non-place creates neither singular nor relations; only solitude, and similitude," he writes. "There is no room there for history unless it has been transformed into an element of spectacle, usually in allusive texts. What reigns there is actuality, the urgency of the present moment. Since non-places are there to be passed through, they are measured in units of time" [Augé 1995, 103104]. As Marta Smagacz notes in her commentary on the concept of Augé, non-places are spaces in which "everything resembles everything", and which Manuel Castells dubbed "spaces of flow" (of people, information, symbols) [Smagacz 2008, 11]. Smagacz characterizes nonplaces as expansive spaces, occupying more and more urban areas, qualitatively homogeneous, unrelated to local culture, but oriented towards its mass dimension. These include, for example, shopping and entertainment centres, multiplexes or airports, which, as she observes, "compete for our attention with sites: urban, residential streets, squares, shops". She also notes that "non-places" begin to pretend to be "places", e.g. in shopping centres there is so-called small architecture, characteristic for traditional city centres, such as benches, fountains, or signposts [Smagacz 2008, 11-12]. Thus, "non-places" are also a manifestation of simulation of space, i.e. by creating cities within a city they become their simulation, the transfer of an urban structure to the artificial surroundings and as such they are deprived of meaning, as their substance are empty signs. Conversely, as one can easily guess, the thing is with noncommercial spaces, they are "archipelagos of islands of meaning in the sea of meaninglessness" [Borysewicz 2008, 16]. An interesting example of "harnessing" non-places, which I propose to juxtapose here with Tarasti's eighth strategy, is the airport in Tallinn. There we will find trees and a playground for children, wood and vegetation, simply unusual elements of an airport. A non-place, which an airport certainly is, acquires "a location" as some foreign elements are introduced into its 
space such as trees, sofas and vegetation resembling urban hedgerows. In this particular case it can also be said that originally the situation here corresponded rather to the second strategy, i.e. $S \vee \mathrm{E}$ "The subject has been disjuncted from its environment; the subject is separated from its milieu" and in a way to respond to this condition, the subject "decided" to resort to the eighth strategy, i.e. quoting Tarasti, $S=\longrightarrow Y$ "The subject tries to dominate its environment $\langle\ldots>$, the subject creates a semiosphere suitable for itself" [Tarasti 2015, 129].

One could certainly point to many other implementations of each of these strategies or relations, which Tarasti included in the nine points. There is no place to discuss each of them in detail and to indicate their possible exemplifications in different cities. We should also be aware that in many cases they will overlap or intersect, because we cannot always make a simple assignment of one relation to one urban area. What I care about at this point in the text is the indication that the relations of the subject with his environment, narrowed down here to urban space, can take different shapes, "forces" can be spread out in different ways, and semiotics tries to capture these relations in a proper way. The subject as the "surrounded" and the environment as the "surrounding" are here clearly indicated functions in the complex semiotic system which is the semiosphere of nature and culture.

\section{The structuralist landscape semiotics}

Having outlined briefly the complex and multidimensional subjectenvironment relations in Tarasti's biosemiotizing approach, we shall move on to considerations which are closer to the semiotic perspective. In Existential Semiotics Tarasti proposes an interesting semiotic theory of landscape, which I would like to discuss briefly here.

"The environment means at the same time the center of something and that 'something' which surround this center" [Tarasti 2000, 154] Tarasti quotes the words of Algirdas-Julien Greimas. The Finn translates this statement, which unambiguously characterizes the relationship between the environment and its centre, into categories of his concept of existential semiotics and states that in its light "center is constituted by the observing subject whom the landscape surrounds" [Tarasti 2000, 154]. As we can see, also in the plane of relations with landscape and environment, a subject remains in the centre here. Transferring the discussed relations into Roman Jakobson's linguistic communication scheme, Tarasti notes that in this case the sender of such a message is the 
surrounding nature; landscape, as an experience, is a message; and the recipient of this sign language of the landscape is the observing subject. Thus - to sum up this part of his ponderings, which are "still general and preliminary", Tarasti states, "landscape semiotics concerns communication between nature and man: The landscape talks to man" [Tarasti 2000 , 155]. First of all, we can see that the structuralism (Jakobson, Greimas) remains the theoretical foundation for this approach, while relations between nature and culture constitute study questions, with particular emphasis on the place occupied by a subject in this whole landscape of relations. The last issue is not surprising if we take into account Tarasti's basic findings of existential semiotics, placing a subject at the centre of his reflections, its dynamics and the changeability of existence, which is discussed below. The structural inclination of this proposal is also evidenced by the assumption of the semiotic character of the phenomena, emphasized by the characteristic terms such as "message", "the landscape talks" or "landscape's language". Similarly, other representatives of various semiotic orientations within structuralism, who wrote about "reading images", (e.g. Umberto Eco, Roland Barthes) or the language of cinema (Yuri Lotman) formulated their concepts. Secondly, Tarasti's statements clearly indicate the opposition between nature and culture. Of course, it is also structuralist "in spirit", but nowadays it is rather approached in semiotics from a different perspective, i.e. within the sub-discipline of biosemiotics already mentioned above.

It is worth following the author of Existential Semiotics in his description of the communication situation, which is the relationship between landscape and the observing subject. Starting with the receiver figure, Tarasti notes that "the receiver can greatly influence the content of the message" [Tarasti 2000, 155]. This is very important for the considerations that are the main focus of this text. The subject, as it turns out, is not a passive observer, and the landscape is not an inviolable space. Landscape can be modified, and the causative power is on the part of the subject. Tarasti adds also that those "messages can be grasped only by a receiver in motion, as when one journeys by sea or wanders in the desert. On the other hand, the landscape itself may be in motion with respect to the observer" [Tarasti 2000, 155]. What is important to emphasize, it is the movement and dynamics of mutual relations that determine the communication situation.

However, a subject is not an isolated entity, on the contrary, it is "a being who acts in and is conditioned by society and culture" [Tarasti $2000,156]$. Therefore, both the relations between man and nature as well as between society and culture should be taken into consideration. 
Consequently Tarasti claims that "landscape is a cultural fact" [Tarasti 2000, 156], so its perception depends on culture. Landscape mediates between nature and culture, or to be precise it belongs to both of these spheres, i.e. it is a border area. Even more so, "it is the humanization of nature, and above all, the transformation of nature into culture" [Tarasti 2000, 156]. Although Tarasti presents examples from the history of landscape painting to illustrate these findings, as in this case he is interested in artistic representations of landscape (including visual arts, but also literature, e.g. Goethe), I will try to show how, in the light of the semiotics of landscape proposed here, the relations between nature and culture are realized in urban space.

Tarasti takes great care not to mix two orders in the description of landscape, i.e. the visual and linguistic representation of a landscape is one thing and landscape as such is yet something different. As a consequence, a clear distinction should be made between the semiotics of landscape as such and the semiotics of the represented landscape. As far as the first case is concerned, landscape itself, as well as its pictorial renderings, should be differentiated from "representational landscapes" conveying cultural units and landscapes which represent only themselves. In the former case Tarasti distinguishes "(1) the level of representation, that is, the landscape in its physical form; (2) the level of represented content, that is, of an aesthetic image or emotional state, which can be called the content of the landscape"; in the latter only one level can be taken into consideration, i.e. the level of landscape itself [Tarasti 2000, 157]. This does not mean, however, that it "escapes" the structuralising order of culture. Referring to Greimas' statement that landscape can be shaped like culture, he gives as an example the Baroque garden, whose organisation reflects the social and theological organisation of culture of that period, i.e. they share the same syntax. It is interesting that the author refers here to "physical form" and "the content" and thus duplicates in a way the findings concerning the construction of sign proposed by Ferdinand de Saussure, the founder of structural semiology. Form as the signifiant and content or meaning as the signifié; the signifying and the signified. Everything here is maintained within the framework of structuralistic optics, just as the surrounding and the surrounded included in the title.

While remaining within the framework of the structural orientation, Tarasti refers further to the findings of researchers representing the Tartu-Moscow Semiotic School, especially from the first years of its activity. This is because he indicates that the sign language of the landscape as such, in itself, corresponds to the primary modelling system, 
while "a landscape description that mirrors this primary language would be called a secondary modelling system" [Tarasti 2000, 158]. Each visual representation of a landscape consists of these two levels of articulation. This interesting reference evokes descriptions of the language of film, theatre or paintings characteristic for the Soviet semiotics. While remaining in this orientation, Tarasti also mentions the perception of a landscape as a text, and thus as requiring decoding and interpretation. When we look at a landscape as a message, encouraged by the above-mentioned reference to Jakobson, the issue of its encoding and decoding arises.

"A landscape can thus be situated in the outer or inner sphere of a culture", Tarasti adds. "In the former case, landscape represents a culture's Otherness, and in the latter case, that which is the Same" [Tarasti 2000, 156]. The following diagram illustrates the intersecting relations of localization and evaluation, allowing to create the basic structure of landscape:

Landscape as a cultural unit

\begin{tabular}{|l|l|l|}
\hline \multicolumn{1}{|c|}{ evaluation } & \multicolumn{1}{|c|}{ positive } & negative \\
\hline localization & & \\
inside, & & \\
\hline Oameness & & \\
Othide, & & \\
\hline
\end{tabular}

Tab. 1. Landscape as a cultural unit [after: Tarasti 2000, 157]

And landscape as cultural unit in the perspective of the signified and signifier:

\begin{tabular}{|c|c|}
\hline \multicolumn{2}{|c|}{ Landscape as cultural unit (level of signified) } \\
\hline $\begin{array}{c}\text { Landscape as physical nature } \\
\text { (level of signifier I) }\end{array}$ & $\begin{array}{c}\text { Landscape description } \\
\text { (level of signifier II) } \\
\text { painting, novel, composition, etc. }\end{array}$ \\
\hline
\end{tabular}

Tab. 2. Landscape as cultural unit (level of signified) [after: Tarasti 2000, 161]

Interestingly, taking into account the cultural landscapes of any Nordic country in the 1990s, Tarasti fills in the first scheme as follows: "(1) Inside (of culture) and positive - environmentally, aesthetically, and functionally well-planned urban landscapes; (2) inside and negative the urban industrial suburb; (3) outside (of culture) and positive - a desert landscape in Lapland; (4) outside and negative - any polluted natural landscape" [Tarasti 2000,157]. These examples, which relate to the 
clearly identified group of countries and time, were supplemented by Tarasti with a suitable type of rural landscape respectively for each of the four categories, which I do not mention here for understandable reasons. However, it would be an interesting study to "present" some selected cities according to this scheme. Without looking far, for example, one could indicate for Poznan the following elements: (1) the revitalised Warta riverside areas, including city beaches, as well as the socalled neighbourhood gardens appearing in various districts of the city. One can also point to districts "restored" to the city, such as Śródka; (2) the Old Market Square, still not functional, because of the uncomfortable surface and nightclubs which have little in common with positively valued entertainment; (3) this element of the scheme seems to be the most difficult to identify within the urban space, as it is hard to indicate a space completely outside culture in this case. Tarasti mentions here desert landscape in Lapland because as we know he does not limit his analysis to urban areas. And finally (4) for example riverside areas waiting to be revitalised. Of course the examples I have mentioned are biased and may be accused of subjectivity, but here they are to serve only as an illustration of Tarasti's theoretical deliberations, and not as an exhaustive analysis from the field of urban studies.

\section{Z-model and the city}

Now it will be a good idea to put our reflections into another perspective, namely to a more individual order, with a clearly exposed figure of a subject, in this text referred to as "the surrounded". In order to do this, one should at least briefly outline the main elements of existential semiotics, which has already been mentioned here several times, but without further elaboration. The project of existential semiotics proposed by Tarasti ${ }^{1}$, was first presented in Existential semiotics (2000), and the in the corrected and extended version in Sein und Schein. Explorations in Existential Semiotics (2015). It is largely based on the assumption of the dynamics of signs and sign systems. Tarasti sees semiotics "in transition, shift, rupture, and flux, something that is «becoming» rather than "being»" [Tarasti 2000, Preface]. Consequently he distinguishes the following fields of study: processes, temporality, signs in flux and pre-signs ("signs in the states before fixation into a sign"). At this stage, the key category for existential semiotics should be introduced, i.e. the category of a subject: “The phenomena of an existential semiotical

\footnotetext{
${ }^{1}$ I elaborate on Tarasti's existential semiotics in: Machtyl 2018 a; Machtyl 2018 b, 194-201.
} 
nature open themselves to a subject only through his / her presence. <...> The interpretation is only possible by being inside the world of Dasein but at the same time transcending it". Transcendence evokes dialectics between 'being' and 'not-being'. Tarasti distinguishes two fundamental acts of transcendence which are at the same time two logical operations: the act of negation and affirmation, linked in turn to "Nothingness" and "Fullness". "Who puts signs in motion?" Tarasti asks and then answers: "The transcending subject, of course, in his act of existing" [Tarasti 2000, 12].

In his earlier book, Tarasti based his concept on the notion of Dasein as well as Being and Doing. Over time he introduced the category of modality, which allowed him to build a dynamic "Z-model" and explore its "inner (emic) notions" [Tarasti 2015, 27]. This made it possible for him to transform the classic Greimas' semiotic square into a "Z-model", also called the "zemic" model. In other words, Tarasti, by updating his design, moves from a static figure in the shape founded by Greimas to a dynamic "Z-model" [Tarasti 2015, 27]. Tarasti complements Greimas' semiotic square with two aspects of being of a subject, i.e. Me and Society (Moi and Soi) and four interpretations of philosophical aspects of being [Tarasti 2015, 227]. " $Z$ " symbolizes a dynamic movement, as he writes between these four aspects, such as body, person (identity), social practice, and values and norms [Tarasti 2015, 227]. "For the simplicity I have numbered these four cases as M1, M2, M3 and M4, and S1, S2, S3 and S4 according to which direction one is going in the model: from a concrete, sensual body towards abstract norms and values, or from these intelligible categories towards their gradual exemplification and corporealisation", Tarasti writes and adds that he considers these two directions of movement within "Z" dynamics as "essential tensions of the ontological semiotics" [Tarasti 2015, 227]. On these ontological foundations, the Finnish semiotician somehow builds modalities, such as: will, can, know and must. For better understanding, we should use the three schemes built by Tarasti (Tab. 3 a, Tab. 3 b, Tab. 4).

Moreover Tarasti claims that signs belong to three worlds: "natural world or 'reality' (which is always already semiotized, i.e., le monde naturel as Greimas said) narration or the world of the text, and its representation in time and place via actors, i.e., performance" [Tarasti 2015, 230]. The model discussed briefly serves Tarasti to describe human Dasein, the most important category of existential semiotics, but it is also successfully applied by its founder to artistic practice, especially, understandably, to music, and also to dance, ballet, fine arts or film. 


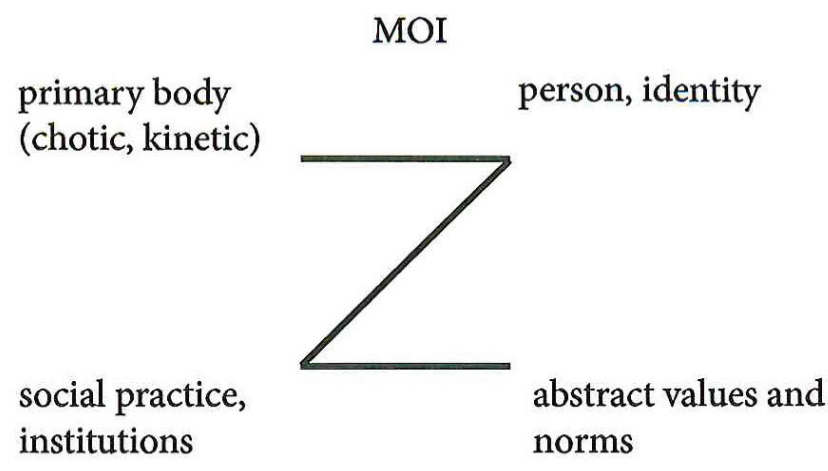

SOI

Tab. 3 a. "Z-model” [after: Tarasti 2015, 228]

MOI

M1 (S4)

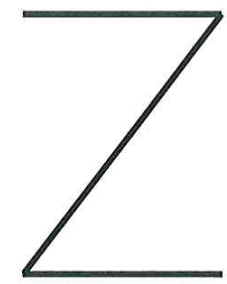

S2 (M3)

S1 (M4)

SOI

M2 (S3)

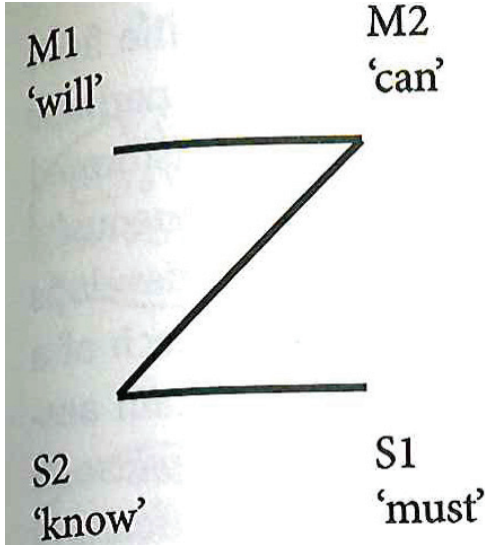

Tab. 4. "Z"-model with modalities [after: Tarasti 2015, 229] of categories [after: Tarasti 2015, 228]

In the light of the discussed relations between nature and culture that I have considered above in the context of landscape and the subject-environment relationship, it is worth mentioning the transition: "Zemic" / "Zetic". Tarasti wonders whether the change within the "Zemic model" from Moi to Soi means the same as the transition from biology to psychology, sociology or anthropology: "or simply from nature to culture"? [Tarasti 2015, 205]. Perhaps, as he considers further, the collective "Zemic" model should actually be called "Zetic", i.e., "external, model to a single subject"? The author of Sein und Schein addresses these issues by invoking the Mikhail Bakhtin notion of dialogue and observes that "Zemic" and "Zetic" remain with each other in a dialogue which is understood precisely in this way. 
The natural element in this model is human in the sense of body, senses and personality, while cultural element involves social practices, norms and values. If we wanted to inscribe in the Z-model ways of subject's existence in urban space, it could be pointed out, for example, that, on the side of M1 and M2 (the will of the subject and its capabilities respectively), we have a causative subject, with its needs and willingness to interfere in urban space, with grassroots actions taken in order to adjust the surrounding space. On the other hand, on S1 and S2 side we have social practices and institutions as well as abstract norms and values. The modalities that remain here for a subject are "know" and "must", i.e. the awareness of norms and values and the need to subordinate to them. In this case, the subject is forced to confront its "will" and "can" with the norms of social life, somehow supervised by various social institutions. As a result of this confrontation, the subject must negotiate his or her own will with society and institutions and adhere to the norms and values required. I believe that it would not be a great misappropriation to juxtapose the pair M1, M2 - S1, S2 with the opposition of tactics-strategy, as described by Michel de Certeau in the structuralist perspective. Let us remind briefly that the author of The Practice of Everyday Life defines strategy as an action resulting from the possessed power, while tactics means an action motivated somehow by the desire to resist, to oppose, to actively engage in a scheme established from above. Certeau links "strategies" with institutions and structures of power, while individuals are acting in environments defined by strategies by using tactics. The author refers to the example of urban space as a space in which the implementation of both strategy and tactics can be observed. The strategy concerns building the city by governments, corporations and various institutions, whereas the tactics will include all actions of the subject that oppose it, such as taking shortcuts, perfectly visible in the city space on beaten paths between officially demarcated streets [Certeau 1984]. When following Certeau we treat the Saussure's langue as strategies and parole as tactics, we will see things in a different light, while still remaining consistently on the ground of structuralism. Saussure's langue, i.e. language system is a set of rules and dictionaries, whereas parole is an individual way of applying them, hence the aspect of acting in the case of tactics (parole) becomes more prominent ${ }^{2}$.

\footnotetext{
${ }^{2}$ It is worth juxtaposing tactics with the notion guerrilla semiotics, proposed by Umberto Eco, to describe the so-called semiotic rebel movement understood as various grassroots movements undertaken by recipients of media transmissions in opposition to their senders acting by means of strategy [Eco 1986].
} 
A noteworthy project focused on the tactical activities of a subject in urban space, i.e., in Tarasti's terminology, a subject operating at M1 and M2 level (will and can), is the Invisible City project, implemented almost a decade ago. The project investigated grassroots actions of residents in large cities, presenting them as active actors of urban spaces ${ }^{3}$. A separate category includes artists who, in various ways, draw attention to the aberrations of urban space with their artistic realizations. It is worth mentioning here the projects of Clet Abraham who interacts with road signs completely changing their message, which is as part of the socalled culture jamming ${ }^{4}$. Another example, again from Poznań, are the realizations of Noriaki in urban space. All these urban activities belong to Moi from "Z-model" proposed by Tarasti, and also to the tactics devised by de Certeau.

\section{The surrounding and the surrounded one more time}

The relations between man and the surrounding environment, in our case that of urban space, are extremely complex. They can be described using various theoretical and methodological points of reference. By choosing the semiotics of culture and its structural inclination we gain an interesting landscape on several levels. In the first plane, i.e. object of research, it turns out that we can interestingly describe human relations with the city against the background of the opposition between nature and culture, then, in more detail, the subject with its surroundings and individuals with the community and institutions. It is also possible to expose its tactical, grassroots initiatives aimed at the realization of its own M1 and M2 in the strategic world of S1 and S2. In the theoretical plane, determined in our case by structural semiotics, we gain quite a satisfactory set of concepts, methods of analyses and a dictionary of the description of the studied phenomenon, and most importantly, it is a coherent set. It turns out that drawing from de Saussure, through Greimas, the Tartu-Moscow semiotics, to Tarasti, we can work out a complete method and language of city description in the context of subject-space relations. The existential semiotics is not a project prepared for the needs of the analysis of the city, but some of its threads worth highlighting in the context of contemporary research on the city, which I have tried to emphasize in this article. Existential semiotics, focused on the subject, turns out to be an effective theoretical basis for

\footnotetext{
${ }^{3}$ See: https://issuu.com/beczmiana/docs/niewidzialne_miasto.

${ }^{4}$ See: https://www.instagram.com/cletabraham/.
} 
the description of dynamic interactions between the subject and its surroundings, while remaining a structuralist project. However, it is structuralist not in the sense of reproducing old concepts, but rather checking the applicability of this trend to various areas of cultural reality, and, in principle, boldly entering into relations with other orientations within the framework of semiotics.

The subject surrounded by its environment and the natural and cultural landscapes around it enter into various dynamic relations with one another. Existential semiotics may be an interesting theoretical research perspective for capturing such relationships, emphasizing their dynamics and multidimensionality, even if the field of interest is narrowed down to the urban space. City and subject - the surrounding and surrounded.

\section{REFERENCES}

Augé 1995 - Augé M. Non-Places: Introduction to an Anthropology of Supermodernity. Transl. into English by J. Howe. London, New York, 1995.

Borysewicz 2008 - Borysewicz P. Miejsca trzecie. Autoportret. Pismo o dobrej przestrzeni. 2008. 2 (23). P. 14-17.

Certeau de 1984 - Certeau de M. The Practice of Everyday Life. Transl. into English by S. Rendall. Berkeley, Los Angeles, London, 1984.

Eco 1986 - Eco U. Towards a Semiological Guerrilla Warfare. Eco U. Travels in hyperreality. Essays. Transl. into English by W. Weaver. San Diego, New York, London, 1986. P. 135-144.

Machtyl 2018 a - Machtyl K. In the Semiotic Network: Signs, Objects and All in Between. CROSS-INTER-MULTI-TRANS-. Proceedings of the 13th World Congress of the International Association for Semiotic Studies. Ed. by D. Martinelli. Kaunas, 2018. P. 415-422.

Machtyl 2018 b - Machtyl K. Sensy i sensualia: o zmysłowe rozszerzenie semiotyki. Semiotyczne wymiary codzienności. Ed. by A. Grzegorczyk, A. Kaczmarek, K. Machtyl. Poznań, 2018. P. 187-202.

Smagacz 2008 - Smagacz M. Miejsca i nie-miejsca. Strategie oswajania. Autoportret. Pismo o dobrej przestrzeni. 2008. 2 (23). P. 10-13.

Tarasti 2000 - Tarasti E. Existential semiotics. Bloomington, 2000.

Tarasti 2015 - Tarasti E. Sein und Schein: Explorations in existential semiotics. Berlin, Boston, 2015. 